\title{
Synthesis of 4-tert-Butyltoluene by Vapor Phase tert- Butylation of Toluene with tert-Butylalcohol over USY Zeolite
}

\author{
Yanming Shen*, Shan Yuan, Lihui Fan, Dongbin Liu, Shifeng Li \\ School of Chemical Engineering, Shenyang University of Chemical Technology, \\ Shenyang 110142, China
}

Received: 17th July 2014; Revised: 31st August 2014; Accepted: 3rd September 2014

\begin{abstract}
Vapour phase tert-butylation of toluene with tert-butylalcohol was studied over ultra-stable Y zeolite (USY) catalyst. The effects of reaction temperature, toluene/TBA molar ratio and liquid space velocity on conversion of toluene and selectivity for 4-tert-butyltoluene were studied. The deactivation and regeneration of the catalyst was also investigated. The results showed that the USY zeolite catalyst offered better toluene conversion of about $30 \%$ and 4 -tert-butyltoluene selectivity of about $89 \%$ at the suitable reaction condition as follows: reaction temperature of $120{ }^{\circ} \mathrm{C}$, toluene/TBA ratio of $2: 1$ and liquid space velocity of $2 \mathrm{ml} / \mathrm{g} \cdot \mathrm{h}$. The clogging of micropores by the formed carbon or oligomers was the main reason for the deactivation of the catalyst. By combustion at $550{ }^{\circ} \mathrm{C}$, the catalyst just lost about $5 \%$ in toluene conversion and about $2 \%$ in para-tert-butyltoluene (PTBT) selectivity. C) 2015 BCREC UNDIP. All rights reserved
\end{abstract}

Keywords: Toluene; Butylation; 4-tert-Butyltoluene; USY; Vapor phase

How to Cite: Shen, Y.M., Yuan, S., Fan, L., Liu, D.B., Li, S.F. (2015). Synthesis of 4-tert-Butyltoluene by Vapor Phase tert-Butylation of Toluene with tert-Butylalcohol over USY Zeolite. Bulletin of Chemical Reaction Engineering \& Catalysis, 10(1): 1-7. (doi:10.9767/bcrec.10.1.7140.1-7)

Permalink/DOI: http://dx.doi.org/10.9767/bcrec.10.1.7140.1-7

\section{Introduction}

4-tert-Butyltoluene (para-tert-butyltoluene, PTBT) has commercial importance as intermediate for production of 4-tert-butylbenzoic acid and 4-tert-butylbenzaldehyde which find applications as modifiers in alkylated resins, in production of fragrances, pharmaceuticals and polymerisation regulators for polyesters [1]. PTBT is produced by alkylation of toluene with alkylating agents such as isobutylene, diisobutylene, MTBE and tert-butyl alcohol (TBA) in the liquid phase. Among these alkylating agents TBA arouses interest because it can be produced from biomass by biochemical route

* Corresponding Author.

E-mail: sym6821@sina.com.cn (Shen, Y. M.),

Telp: +86-24-89383529, Fax: +86-24-89383760 which is a potentially superior alternative to the petrochemical route $[2,3]$. In production of PTBT in liquid phase, the common used homogeneous acid catalysts are $\mathrm{H}_{2} \mathrm{SO}_{4}, \mathrm{HF}, \mathrm{H}_{3} \mathrm{PO}_{4}$, etc., which are not environmentally benign, not re-usable and also lead to corrosion of the equipment $[1,4]$. Therefore, considerable attention has been devoted for the development of solid acid catalysts, which are environmentally more acceptable.

Zeolites, as one of the acid catalysts, are widely used in alkylation of hydrocarbons in petrochemistry owing to their acidity and shape selectivity. Some zeolites such as $\mathrm{H}$ mordenite (H-M) [5, 6], H-Y [7], H-beta (H- $\beta$ ) [7], (Zn)-Al-MCM-41 [1, 8], Ce-H-M [5] have been reported for tert-butylation of toluene in liquid phase. Though higher conversion of tolu- 
ene and selectivity of PTBT were obtained, in the above reports this reaction was carried out in batch operation, which is not suitable for large-scale production. tert-Butylation of toluene in vapor phase has attracted researcher attention. Sebastian et al. [9] investigated the effect of acidity on regio-selective tert-butylation of toluene with tert-butyl alcohol (TBA) over high silica mordenite catalysts with varying silica - alumina ratio in the vapour phase and in the reaction temperature range $140-160{ }^{\circ} \mathrm{C}$. They obtained the best results over commercial $\mathrm{H}-\mathrm{M}$ zeolite with $\mathrm{Si} / \mathrm{Al}=90$ with conversion of toluene $18 \%$ and selectivity to PTBT $67 \%$ at $160{ }^{\circ} \mathrm{C}$ and at the molar ratio TBA/toluene of $1: 8$ and at WHSV $=3 \mathrm{~h}^{-1}$. Pai et al. [4] studied vapour phase alkylation of toluene with tertbutyl alcohol over the large pore zeolites HB, HY and H-MCM-22. The effect of the acidity, reaction temperature, run duration, feed rate (WHSV) and molar ratio of the reactants on conversion of toluene and selectivity for 4-tertbutyl toluene was discussed. It was showed that that order of catalytic activity was $\mathrm{H} \beta \approx$ HY > MCM-22. The toluene conversion of about $20 \%$ and PTBT selectivity of about $85 \%$ were observed over $\mathrm{HY}$ at reaction temperature of $393 \mathrm{~K}$, WHSV of $2 \mathrm{~h}^{-1}$, toluene:TBA $=4: 1$. It was also found that the para-isomer was the predominant product, followed by the metaisomer, while no ortho-isomer was found in the products due to steric factors.

In a previous study [10], toluene butylation in vapor phase under atomospheric pressure over $\mathrm{NaOH}$ modified $\mathrm{H}$-mordenite catalyst with silica to alumina ratio of 30 has reported. The toluene conversion of $33 \%$ and PTBT selectivity of $81 \%$ was obtained at conditions as follows: reaction temperature was $180{ }^{\circ} \mathrm{C}$, mass liquid space velocity was $4 \mathrm{ml} / \mathrm{g} \cdot \mathrm{h}$, and toluene/TBA ratio was 2 . In the present study, we investigate the tert-butylation of toluene over largepore zeolite USY zeolite. The effects of reaction temperature, mass liquid space velocity and toluene/TBA ratio is evaluated. The analysis for deactivation and regeneration of the catalyst is also discussed in this work.

\section{Materials and Methods}

\subsection{Materials}

The toluene and tert-butylalcohol (TBA) used in this study are of analytical reagent grade and obtained from Sinopharm Chem Ltd, China. They were used without further purification. Reference standards used for gas chromatographic analysis were obtained from Sigma-Aldrich Corporation. Zeolite ultra-stable
Y (USY) was obtained from Nankai Catalyst Company (China) as crystalline, binderless powder.

\subsection{Characterization}

The crystallinity and phase purity of the zeolite samples were evaluated by powder XRD (Bruker ADVANCED D8) using monochromatized $\mathrm{Cu} \mathrm{Ka}(40 \mathrm{kVA}, 40 \mathrm{~mA}) \mathrm{X}$-rays. The TG-DTA experiments were carried out on a HCT-1 analyzer (Beijing Henven Scientific Instrument Factory, China) in the temperature range of $25-800{ }^{\circ} \mathrm{C}$ at a heating rate of $10{ }^{\circ} \mathrm{C}$ /min. BET surface area measurements were carried out on a V-sorb $2800 \mathrm{P}$ instrument (Gold-APP, China) by nitrogen sorption at -196 ${ }^{\circ} \mathrm{C}$. Prior to the sorption of $\mathrm{N}_{2}$, the samples were heated in vacuum at $200{ }^{\circ} \mathrm{C}$ for $3 \mathrm{~h}$.

\subsection{Butylation reaction procedure and product analysis}

Butylation of toluene was carried out at atmospheric pressure, in a fixed bed, down flow, integral stainless steel reactor. Prior to the reaction, the catalyst was calcined at $550{ }^{\circ} \mathrm{C}$ for 3 h. About $2 \mathrm{~g}$ of catalyst $(20-40 \mathrm{mesh})$ was placed at the center of the reactor supported by quartz wool and porcelain beads. The reactor was placed vertically in a furnace controlled by temperature programmers. Liquid reactant mixture containing toluene and TBA was fed with a micro-flow pump (LB-05C, Xingda, China). The reaction products were condensed using chilled water condenser and the samples were collected at regular intervals. The products were analysed by GC (SP3420, Ruili, China) equipped with FID and capillary column (SE-30, $30 \mathrm{~m}, 0.32 \mu \mathrm{m}$ film thickness). The conversion of toluene and selectivity of products were calculated according to the Equations (1).

Conversion of toluene (mol\%):

$$
x \%=\frac{(\text { toluene })_{\text {in }}-(\text { toluene })_{\text {out }}}{(\text { toluene })_{\text {in }}} \times 100 \%
$$

Selectivity of products (mol\%):

$$
S_{i} \%=\frac{(\text { corrected area })_{i}}{\text { sum of corrected areas of products }} \times 100 \%
$$




\section{Results and Discussion}

\subsection{Mechanism of tert-butylation of tolu- ene with tert-butylalcohol}

The tert-butylation of toluene with TBA is an electrophilic substitution reaction on the aromatic ring. The tert-butylation reactions catalyzed by acids or solid acid zeolites are commonly considered to proceed via carbenium ion mechanisms [1]. Several acid-catalysed equilibrium reactions take place in the process of toluene alkylation by tert-butanol, as showed in Figure 1 [7]. The first reaction is the dehydration of tert-butanol to iso-butylene, which is then protonated by the catalyst to form tertbutyl carbocation. The carbocation further reacts with toluene in the presence of the catalyst to form 4-tert-butyltoluene (PTBT), 3-tertbutyltoluene (MTBT) and 2-tert-butyltoluene (OTBT). The formed MTBT reacts with the carbocation over the catalyst to form 3,5-di-tbutyltoluene. Excess isobutylene further reacts with each molecule over the catalyst to form oligomers, while the oligomers (R-alkyl groups) react with excess toluene in the presence of the catalyst to form alkyltoluenes with longer alkyl chains. The remaining oligomers further react with water over the catalyst to form alcohols. All the above products are obtained with respect to the catalytic properties along with optimal reaction conditions.

\subsection{The effect of reaction temperature}

The effect of reaction temperature was investigated on the USY calcined at $550{ }^{\circ} \mathrm{C}$. The results were shown in Figure 2. It was found that the products were mainly composed of un-

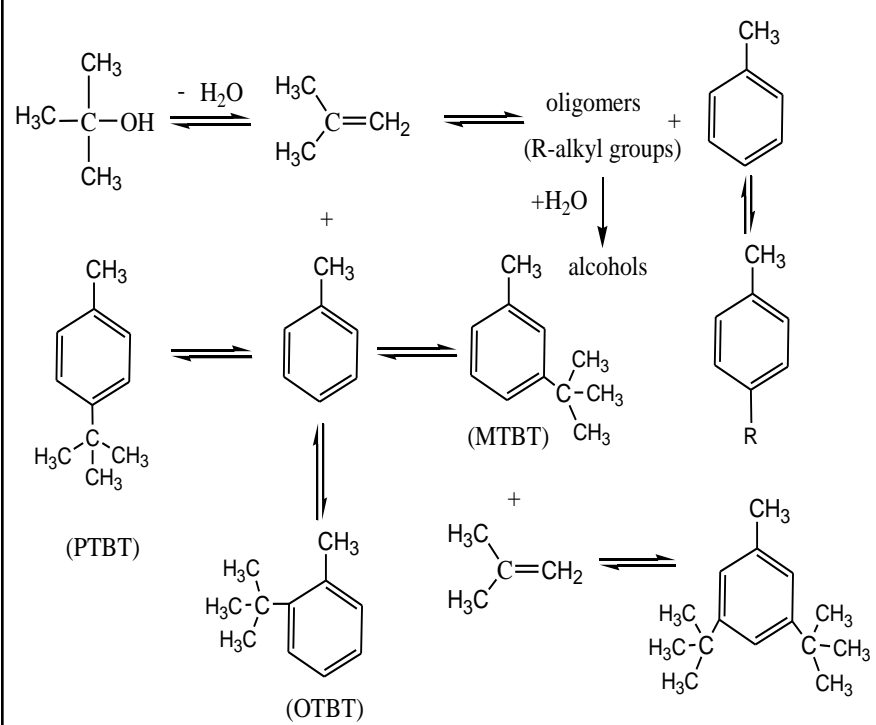

Figure 1. Reaction scheme of tert-butylation of toluene with TBA. reacted toluene and TBA, $\mathrm{PTBT}$, meta-tertbutyltoluene (MPBT), and trace ortho-tertbutyltoluene (OPBT) and other oligomers. From Figure 2, it can be seen that the conversion of toluene increases from about $4 \%$ to about $31 \%$ when the reaction temperature increases from 90 to $120{ }^{\circ} \mathrm{C}$. When the reaction temperature further increases to 150 and 180 ${ }^{\circ} \mathrm{C}$, the toluene conversion keeps the higher value $(20 \sim 40 \%)$ in the initial stage up to $3 \mathrm{~h}$, then it drops to a rather lower value $(\sim 6 \%)$. This may be caused the deactivation by the carbon deposition reaction which will be illustrated later. The TPBT selectivities are about $89 \%$ at reaction temperatures of 90 and $120{ }^{\circ} \mathrm{C}$, respectively, but decrease to $50 \sim 60 \%$ with increasing reaction temperature to 150 and 180 ${ }^{\circ} \mathrm{C}$ due to the formation of by-products such as MTBT, xylene, benzene, etc. It is also observed that the toluene conversion and PTBT selectivity keeps stable at reaction temperature of 120 ${ }^{\circ} \mathrm{C}$, which is chosen as the optimal reaction temperature to investigate other effects in the later experiments.

\subsection{The effect of toluene/TBA ratio}

In order to investigate the effect of toluene/TBA ratio on the toluene conversion and selectivities of products, the toluene/TBA ratios of $1: 2,1: 1,2: 1$ and $4: 1$ were chosen and the results are listed in Table 1. It may be seen that the toluene conversion increases with the increase in toluene/TBA up to the ratio of $2: 1$, then it slightly decreases. It may be explained that as the concentration of TBA in the feed in-

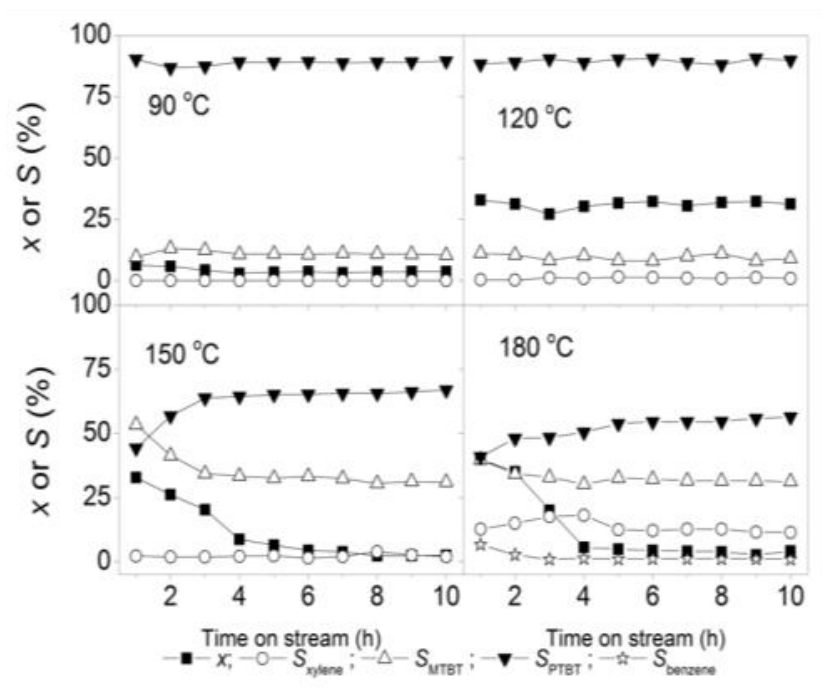

Figure 2. The effect of reaction reaction temperature on the conversion $(x)$ and selectivities of products $(S)$. Reaction conditions: toluene/TBA ratio of $2: 1$, liquid space velocity of 2 $\mathrm{ml} / \mathrm{g} \cdot \mathrm{h}$. 
creases, the aliphatics concentration in the product increases. At higher TBA concentrations, the oligomerisation of isobutylene that is formed on dehydration of TBA is in competition with the main alkylation reaction. The lower utilization of the alkylating agent leads to a fall in the alkylation selectivity with higher TBA containing feeds [4]. It also should be noted that the produced isobutylene could not be condensated in our present experimental system, so it was not analyzed in the products. In addition, the higher concentration of TBA in the feed leads to the formation of by-products such as MTBT and OTBT. The higher PTBT selectivity of $89.58 \%$ was obtained at toluene/TBA ratio of $2: 1$, which is considered the suitable value.

\subsection{The effect of liquid space velocity}

Space velocity or contact time is an important parameter as it not only influences the conversion of a reactant, it also leads to changes in selectivity of various products. Diffusion constraints have a bearing on product shape selectivity, which in turn govern the product pattern, particularly in a zeolite driven catalytic process. Space velocity also influences the secondary and consecutive reactions. As a result, desired selectivity to a particular product can be achieved by choosing a right space velocity [9]. The effect of space velocity on toluene conversion and selectivity of products is given in Table 2. The toluene conversion decreases with increasing the space velocity. This may be due to the fact that, at higher space velocity, a lower contact time favours the oligomerisation of isobutylene rather than the toluene alkylation reaction [4]. However, the PTBT selectivity does not exhibit a notable change, seemingly reaches the maximum value of about $89 \%$ at liquid space velocities of $2 \sim 3$ $\mathrm{ml} / \mathrm{g} \cdot \mathrm{h}$.

\subsection{Stability of the catalyst}

The stability of the catalyst is an important factor for the practice. The toluene conversion and PTBT selectivity on USY catalyst were investigated over $50 \mathrm{~h}$. The results are shown in Figure 3. It is observed that the toluene conversion do not present notable change till reaction time of $32 \mathrm{~h}$. The notable drop in toluene conversion is found at the reaction time of $50 \mathrm{~h}$. There is no notable change in PTBT selectivity throughout reaction for $50 \mathrm{~h}$. The reduction in toluene conversion is probably attributed to the formation of coke on the catalysts, which was observed in alkylation of aromatics with alcohols on zeolite catalysts [9]. While the slight reduction in PTBT selectivity can be attributed to product shape selectivity effects resulting from coke deposition at pore mouths of these zeolites [7].

\subsection{Regeneration of the deactivated cata- lyst}

In order to investigate the deactivation of the catalyst in detail, the characterization for the fresh and deactivated catalysts were carried out. Figure 4 shows the XRD patterns of fresh and used catalyst for $50 \mathrm{~h}$. It can be seen

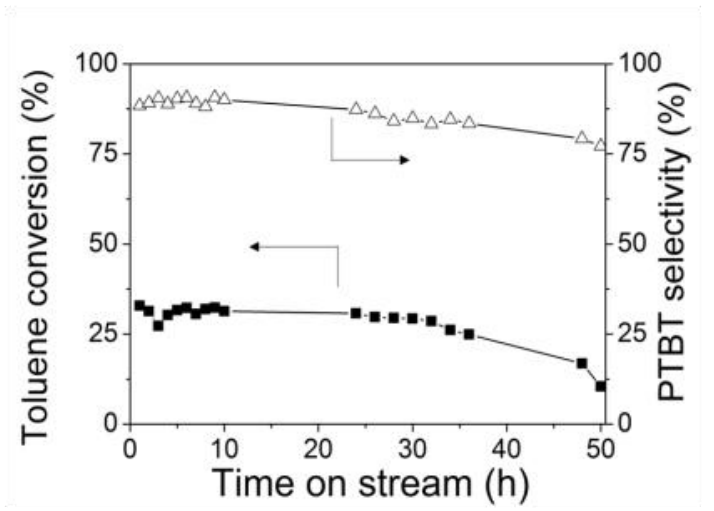

Figure 3. The variations of toluene conversion and PTBT selectivity with time on stream.

Table 1. The effect of toluene/TBA ratio on the conversion and selectivities for products

\begin{tabular}{cccccc}
\hline \multirow{2}{*}{$\begin{array}{c}\text { Toluene / TBA ratio } \\
(\mathrm{mol} / \mathrm{mol})\end{array}$} & Conversion (\%) & \multicolumn{4}{c}{ Selectivity (\%) } \\
\cline { 3 - 6 } & & xylene & OTBT & MTBT & PTBT \\
\hline $1: 2$ & 16.17 & 1.27 & 3.35 & 12.69 & 82.68 \\
$1: 1$ & 15.58 & 3.69 & 1.94 & 13.98 & 80.39 \\
$2: 1$ & 31.17 & 0.94 & 0 & 9.49 & 89.58 \\
$4: 1$ & 27.55 & 0.38 & 0 & 10.10 & 89.51 \\
\hline
\end{tabular}

Reaction conditions: reaction temperature of $120^{\circ} \mathrm{C}$, liquid space velocity of $2 \mathrm{ml} / \mathrm{g} \cdot \mathrm{h}$. 
that the fresh catalyst presents a typical diffraction peaks of zeolite Y (JCPDF 43-0168) [11]. Compared to that of fresh catalyst, there are no new diffraction peaks exhibit in the XRD pattern of catalyst used for $50 \mathrm{~h}$, and the positions of diffraction peaks do not change, showing no new phases formed during the reaction. However, the intensities of (111) and (220) diffraction peaks decrease, indicating the crystallinity of the used USY had slightly decreased, probably owing to the deposition of oligomers or coke at pore mouths of the zeolite catalyst [9]. In contrast to reduced peak intensities, the diffraction peaks intensity of (311), (642), (555) of the used USY zeolite contrarily enhanced, which showed that the slightly effects on the structure of used USY compared with fresh USY [12].

Figure 5 shows the TG-DTA curves of the fresh, used regenerated catalysts. It is observed that for the fresh catalyst there is only one weight-loss stage with the percentage of about $20 \%$, attributed to the loss of absorbed water. For the used catalyst, there are three weightloss stages. The first stage $\left(<165{ }^{\circ} \mathrm{C}\right)$ is attributed to the loss of adsorbed water, giving the weight-loss percentage of about $5 \%$. The second stage ranging from 165 to $370{ }^{\circ} \mathrm{C}$, with the weight-loss percentage of about $6 \%$, is originated from the combustion of relatively light carbonaceous compounds. This combustion gives a exothermic peak in DTA curve. The third stage ranging from 370 to $600{ }^{\circ} \mathrm{C}$ is due to the combustion of heavily polymerised carbonaceous material, formed directly during catalyst coking or maybe during the oxidation of the lighter carbonaceous compounds [13]. This combustion presents a broad exothermic peak in DTA curve and contributes weight-loss percentage of about $11 \%$. Generally, the deactivated catalyst can be regenerated by combustion and solvent extraction [14]. In this article, the deactivated catalyst was regenerated by combustion at $550{ }^{\circ} \mathrm{C}$ in air. The TG-DTA curve for the regenerated catalyst (see Figure 4) exhibits the similar profile with that of the fresh catalyst, suggesting the complete removal of deposited carbon or oligomers.

Figure 6 shows the adsorption-desorption isotherms and pore diameter distributions of fresh, used and regenerated catalysts obtained from $\mathrm{N}_{2}$ adsorption. According to the IUPAC definition, mesoporous materials exhibit a type IV adsorption-desorption isotherm. The isotherm of the fresh zeolite exhibits a large uptake of $\mathrm{N}_{2}$ at a very low relative pressure, indi-

Table 2. The effect of liquid space velocity on the conversion and selectivities for products

\begin{tabular}{cccccc}
\hline \multirow{2}{*}{$\begin{array}{c}\text { Liquid space } \\
\text { velocity } \\
(\mathrm{ml} / \mathrm{g} \cdot \mathrm{h})\end{array}$} & Conversion (\%) & \multicolumn{5}{c}{ Selectivity (\%) } \\
\cline { 3 - 6 } 1 & 33.88 & 0.23 & 0 & MTBT & PTBT \\
\hline 2 & 31.17 & 0.94 & 0 & 9.49 & 87.62 \\
3 & 25.94 & 1.60 & 0 & 10.00 & 89.58 \\
4 & 22.27 & 2.99 & 0 & 9.84 & 88.40 \\
\hline
\end{tabular}

Reaction conditions: reaction temperature of $120^{\circ} \mathrm{C}$, toluene/TBA ratio of $2: 1$.

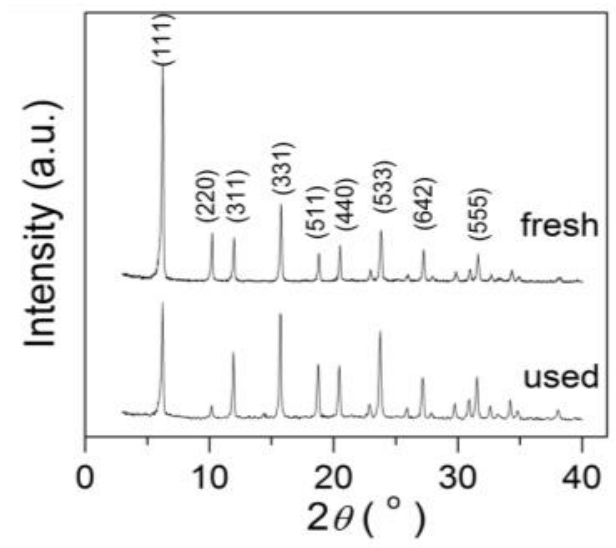

Figure 4. XRD patterns of fresh and used catalyst for $50 \mathrm{~h}$.

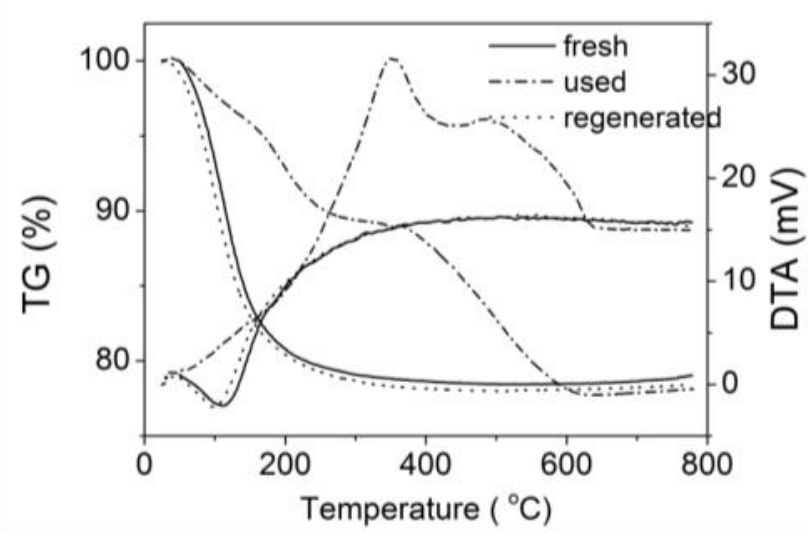

Figure 5. The TG-DTA curves of fresh, used for $50 \mathrm{~h}$ and regenerated catalysts. 
cating the presence of significant microporosity [15]. Such microporosity is still observed for the used catalyst, but the amounts greatly decreases, showing the loss in the amounts of micropore after used for $50 \mathrm{~h}$. The pore distribution curves in Figure 6 clearly indicate that the fresh catalyst is mainly composed of micropores $(0.4 \sim 1 \mathrm{~nm})$, but the used catalyst exhibits the pore distribution ranging from 0.7 to $7.9 \mathrm{~nm}$. The BET surface area and the micropore volume of fresh, used and regenerated catalyst are tabulated in Table 3. It is seen that for the fresh catalyst the specific surface area (597.25 $\mathrm{m}^{2} / \mathrm{g}$ ) is mainly origined from micropores, which volume occupies $60.92 \%$ of the total volume. After being used for $50 \mathrm{~h}$, the volume of micropores reduces greatly to $7.44 \%$ of the total volume and the specific surface area decreases to $71.38 \mathrm{~m}^{2} / \mathrm{g}$. This result implies that the deposition of carbon or oligomers mainly locates in micropores. By combustion at $550{ }^{\circ} \mathrm{C}$ the deposited carbon or oligomers can be removed from the micropores, as a result the micropore volume increases to $53.93 \%$ of the total volume,

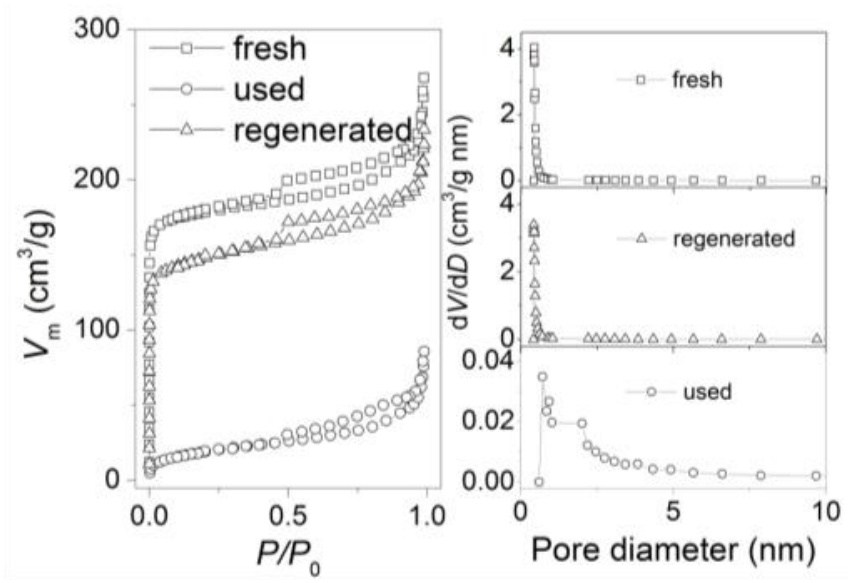

Figure 6. The adsorption-desorption isotherms and pore diameter distributions of fresh, used for $50 \mathrm{~h}$ and regenerated catalyst. which is close to that of the fresh catalyst (see Table 3).

The catalytic activity of the regenerated catalyst was investigated, and the results are shown in Figure 7. It is found that the regenerated catalyst loses about 5\% in toluene conversion and about $2 \%$ in PTBT selectivity, implying that the regenerated catalyst maintains its catalytic performance as fresh catalyst.

In summary, the carbon deposition is the main reason for the loss of catalytic performance. The deposited carbon can be removed by calcination in air and the catalytic performance can be rehabilitated. The later work should focus on the improvement on the stability and life of the catalyst. This could be achieved by reducing the acidity which is the main reason for carbon deposition.

\section{Conclusions}

Alkylation of toluene with tert-butyl alcohol was investigated on USY catalyst. The catalytic performance was influenced by reaction temperature, toluene/TBA ratio and liquid space

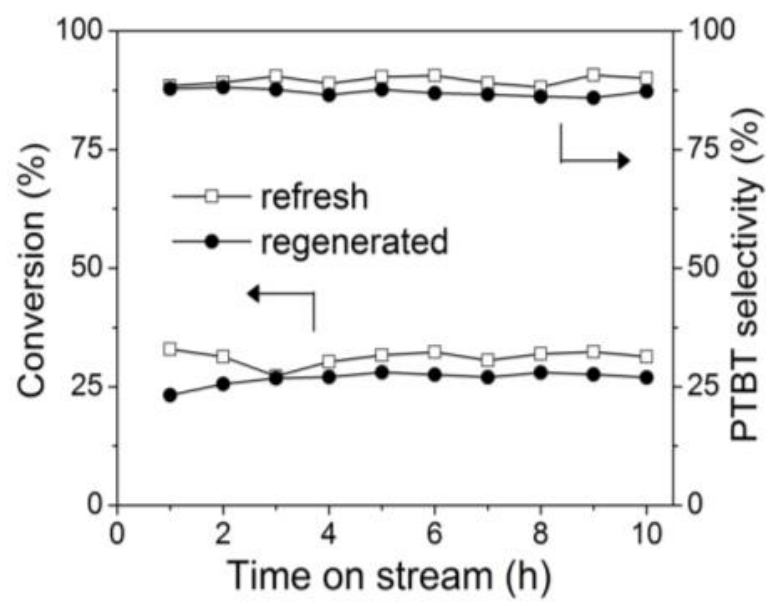

Figure 7. The comparison on the catalytic performance of the regenerated catalyst with that of the fresh catalyst. Reaction conditions: reaction temperature of $120{ }^{\circ} \mathrm{C}$, toluene/TBA ratio of $2: 1$, liquid space velocity of $2 \mathrm{ml} / \mathrm{g} \cdot \mathrm{h}$.

Table 3. The specific area and pore structure for fresh, used and regenerated catalysts

\begin{tabular}{cccccccc}
\hline \multirow{2}{*}{ Catalyst } & \multicolumn{3}{c}{ Specific surface area $\left(\mathrm{m}^{2} / \mathrm{g}\right)$} & & \multicolumn{3}{c}{ Pore volume $\left(\mathrm{cm}^{3 / \mathrm{g}}\right)$} \\
\cline { 2 - 4 } & Total & Micropore & Percentage & & Total & Micropore & Percentage \\
\hline Fresh & 597.25 & 540.68 & 90.53 & & 0.4145 & 0.2525 & 60.92 \\
Used & 71.38 & 23.65 & 33.13 & & 0.1330 & 0.0099 & 7.44 \\
Regenerated & 499.74 & 417.75 & 83.59 & & 0.3614 & 0.1949 & 53.93 \\
\hline
\end{tabular}

a Percentage of micropore, \%. 
velocity. High reaction temperatures are not favourable for obtaining good toluene conversion and PTBT selectivity, and the suitable reaction temperature is $120{ }^{\circ} \mathrm{C}$. Feeds containing lower concentration of TBA are better suited for attaining high toluene conversion and PTBT selectivity, which maximum values are obtained at toluene/TBA ratio of $2: 1$. The suitable liquid space velocity is $2 \sim 3 \mathrm{ml} / \mathrm{g} \cdot \mathrm{h}$. The deactivation of the catalyst is mainly attributed to clogging of micropores by the formed carbon or oligomers. By combustion at $550{ }^{\circ} \mathrm{C}$, the deactivated catalyst can maintain its catalytic performance as fresh catalyst. The USY zeolite catalyst offers better toluene conversion and PTBT selectivity and has potential application in vapor phase tert-butylation of toluene with tert-butylalcohol. The future work should focus on the improvement on the stability and life of the catalyst by modification to USY zeolite.

\section{References}

[1] Selvaraj, M., Jeon, S. H., Han, J., Sinha, P. K. and Lee, T. G. (2005). A novel route to produce 4-t-butyltoluene by t-butylation of toluene with t-butylalcohol over mesoporous Al-MCM41 molecular sieves. Applied Catalysis A: General 286(1): 44-51.

[2] López Contreras, A. M., Kuit, W., Siemerink, M. A. J., Kengen, S. W. M., Springer, J. and Claassen, P. A. M. (2010). Production of longer-chain alcohols from lignocellulosic biomass: butanol, isopropanol and 2,3-butanediol. Bioalcohol Production. K. Waldron, Woodhead Publishing: 415-460.

[3] Raganati, F., Olivieri, G., Procentese, A., Russo, M. E., Salatino, P. and Marzocchella, A. (2013). Butanol production by bioconversion of cheese whey in a continuous packed bed reactor. Bioresource Technology 138: 259-265.

[4] Pai, S., Gupta, U. and Chilukuri, S. (2007). Butylation of toluene: Influence of zeolite structure and acidity on 4-tert-butyltoluene selectivity. Journal of Molecular Catalysis A: Chemical 265(1-2): 109-116.

[5] Kostrab, G., Mravec, D., Bajus, M., Janotka, I., Sugi, Y., Cho, S. J. and Kim, J. H. (2006). tertButylation of toluene over mordenite and cerium-modified mordenite catalysts. Applied Catalysis A: General 299: 122-130.

[6] Zhou, Z., Wu, W., Wang, J. and Zeng, C. (2009). Tert-butylation of Toluene with Tertbutyl Alcohol over Realuminated H-mordenite Zeolite. Chinese Journal of Chemical Engineering 17(2): 195-199.
[7] Mravec, D., Zavadan, P., Kaszonyi, A., Joffre, J. and Moreau, P. (2004). Tert-butylation of toluene over zeolite catalysts. Applied Catalysis A: General 257(1): 49-55.

[8] Selvaraj, M. and Lee, T. G. (2005). tButylation of toluene with t-butyl alcohol over mesoporous Zn-Al-MCM-41 molecular sieves. Microporous and Mesoporous Materials. 85(12): 59-74.

[9] Sebastian, C. P., Pai, S., Sharanappa, N. and Satyanarayana, C. V. V. (2004). Regio selective butylation of toluene on mordenite catalysts: influence of acidity. Journal of Molecular Catalysis A: Chemical. 223(1-2): 305-311.

[10] Wang, C., Fan, L., Shen, Y., Liu, D. and Xu, S. (2012). Gas-phase Synthesis of para-tertbutyltoluene from Toluene and tert-Butyl Alcohol over H-Mordenite Catalyst. Chemical Reaction Engineering and Technology (China) 28: 50-56.

[11] Parise, J. B., Corbin, D. R., Abrams, L. and Cox, D. E. (1984). Structure of dealuminated Linde Y-zeolite; Si139.7Al52.30384 and Si173.1Al18.90384: presence of nonframework Al species. Acta Crystallographica Section C. 40(9): 1493-1497.

[12] Wang, H., Yu, D., Sun, P., Yan, J., Wang, Y. and Huang, H. (2008). Rare earth metal modified NaY: Structure and catalytic performance for lactic acid dehydration to acrylic acid. $\mathrm{Ca}$ talysis Communications. 9(9): 1799-1803.

[13] Rossetti, I., Bencini, E., Trentini, L. and Forni, L. (2005). Study of the deactivation of a commercial catalyst for ethylbenzene dehydrogenation to styrene. Applied Catalysis A: General. 292: 118-123.

[14] Maldonado-Hódar, F. J., Ribeiro, M. F., Silva, J. M., Antunes, A. P. and Ribeiro, F. R. (1998). Aromatization ofn-Heptane on Pt/Alkali or Alkali-Earth Exchanged Beta Zeolite Catalysts: Catalyst Deactivation and Regeneration. Journal of Catalysis. 178(1): 1-13.

[15] Radwan, A. M., Kyotani, T. and Tomita, A. (2000). Characterization of coke deposited from cracking of benzene over USY zeolite catalyst. Applied Catalysis A: General. 192(1): 43-50. 